УДК 616.132.2089.168

\title{
Непосредственные и среднесрочные результаты операций аортокоронарного шунтирования в условиях Центра экстренной помощи
}

\author{
Хаджибаев А. М., Обейд М. А., Абдурахманов А. А., Машрапов О. А., \\ Рахимов Н. М., Абдухалимов И. А., Сабиров С. И., Ганиев У. Ш.
}

Республиканский научный центр экстренной медицинской помощи (Ташкент, Узбекистан)

\begin{abstract}
Статья посвящена анализу результатов операций аортокоронарного шунтирования. Исследование проводилось в Республиканском научном центре экстренной медицинской помощи. В исследовании авторы анализировали непосредственные и среднесрочные результаты off-pump АКШ, включая ранние послеоперационные осложнения и смертность у 692 больных с ИБС, которым была проведена операция АКШ за период с 2013 по 2018 годы (женщин - 160 (23,1\%), мужчин - $532(76,9 \%)$, средний возраст $56,04 \pm 0,9$ лет). В большинстве случаев $(658 ; 95,1 \%)$ хирургическая реваскуляризация производилась на работающем сердце. Частота конверсии на on-pump составила 4,9\%. Индекс шунтирования составил 3,6 , ранняя послеоперационная летальность $-2,5 \%$. Факторами риска развития летального исхода явились конверсия на on-pump по экстренным показаниям и нестабильная гемодинамика при поступлении. Выживаемость больных за период наблюдения до 40 месяцев составила 97,3\%. Свобода от возвратной стенокардии составила 90,8\%, свобода от повторных реваскуляризаций $-98,2 \%$. Результаты исследования позволяют сделать вывод о том, что хирургическая реваскуляризация миокарда у больных с многососудистым поражением сопровождается низкой частотой послеоперационных осложнений, относительно низкой летальностью в раннем и среднесрочном периоде наблюдения. АКШ сопровождается удовлетворительными показателями свободы от возвратной стенокардии и свободы от реваскуляризации.
\end{abstract}

Ключевые слова: аортокоронарное шунтирование (АКШ), лечение ишемической болезни сердца (ИБС), АКШ с использованием искусственного кровообращения (ИК - оп-ритр), АКШ на работающем сердще (оff-ритр).

Аортокоронарное шунтирование (АКШ) занимает особое место в лечении ишемической болезни сердца (ИБС). Его эффективность в устранении симптомов стенокардии и увеличении продолжительности жизни у некоторых групп пациентов в настоящее время неоспорима. Различают два метода хирургической реваскуляризации миокарда - стандартную процедуру АКШ с использованием искусственного кровообращения (ИК - on-pump) и АКШ на работающем сердце (off-pump) [1, 2]. С конца 1990-х годов АКШ на работающем сердце стало приобретать все большую популярность, что связано с появлением приспособлений, стабилизирующих сердце для наложения анастомоза $[2,3,6]$. В литературе, в том числе в современных периодических публикациях, ведется активная дискуссия о том, какой из методов предпочтительнее. Ряд авторов указывают на низкую эффективность off-pumpАКШ, связанную с риском неполной реваскуляризации и, как следствие, периоперационного инфаркта миокарда и отдаленной несостоятельности графтов [3, 6, 7, 14]. Другие авторы подчеркивают отсутствие статистически достоверных различий в частоте летальности, послеоперационных осложнений, инфаркта и инсульта в послеоперационном периоде, а также в отношении других преимуществ и недостатков при сравнении обоих методов, подчеркивая одинаковую продолжительность функционирования шунтов в отдаленном периоде $[10,13,14,17]$. Некоторые исследователи обращают внимание на эффективность и безопасность метода на работающем сердце у пациентов как с низким, так и с высоким риском $[4,5,8,9$, $15,16]$. В частности, согласно последним публикациям, реваскуляризация миокарда в соответствии с методикой off-pump сопровождается коротким периодом пребывания в отделении интенсивной терапии, снижением времени вентиляции и нахождения в клинике, низкую по сравнению с конвенционным АКШ частоту фибрилляции предсердий, переливаний крови и ее компонентов, низкую потребность в инотропной поддержке, низкую частоту инфекций дыхательных путей, инсульта, делирия и энцефалопатии, а также послеоперационного инфаркта миокарда [4].

Цель публикации - анализ непосредственных и среднесрочных результатов АКШ.

Материалы и методы исследования. В представленном ретроспективном исследовании проанализированы истории 692 больных ИБС, оперированных в отделении кардиохирургии Республиканского научного центра экстренной медицинской помощи в 2013-2018 годах. Исходные показатели больных приведены в табл. 1. 


\section{Таблица 1}

Показатели больных, включенных в исследование (n=692)

\begin{tabular}{lc} 
Критерии & Показатели \\
\hline Средний возраст, годы & $56,04 \pm 0,9$ \\
\hline Мужчины & $532(76,9 \%)$ \\
\hline Женщины & $160(23,1 \%)$ \\
\hline Нестабильная стенокардия & $680(98,3 \%)$ \\
\hline Острый инфаркт миокарда & $12(1,7 \%)$ \\
\hline Продолжительность заболевания более & $577(83,4 \%)$ \\
\hline года & $505(73,0 \%)$ \\
\hline ОИМ в анамнезе & $470(67,9 \%)$ \\
\hline Похарный диабет & $650(93,9 \%)$ \\
\hline ХОБЛ & $36,30 \%$ \\
\hline ФВ\% & $44,6 \pm 4,3 \%$
\end{tabular}

Больных женского пола было 160 (23,1\%), мужского - $532(76,9 \%)$, средний возраст пациентов составил $56,04 \pm 0,9$ года. Продолжительность заболевания более 1 года отмечена у $83,4 \%$ больных. У $73 \%$ больных имелся перенесенный острый инфаркт миокарда в анамнезе. Сахарный диабет диагностирован у 67,9\% больных, сократительная способность миокарда была умеренно снижена и составила $44,6 \pm 4,3$. Большинство больных $(680 ; 98,3 \%)$ оперировано на фоне нестабильной стенокардии, у остальных 12 (1,7\%) при поступлении диагностирован острый инфаркт миокарда.

Хирургический доступ во всех случаях обеспечивали посредством срединной стернотомии. В соответствии с принятой в отделении практикой в большинстве случаев (658; 95,1\%) хирургическая реваскуляризация производилась на работающем сердце. Для позиционирования сердца применяли стандартные глубокие швы на перикард, положение Транделенбурга, повороты операционного стола, объемную нагрузку и/или кардиотоническую поддержку для обеспечения гемодинамической стабильности. Для стабилизации миокарда использовали оригинальный механический стабилизатор давления (рис. 1).

В случаях нестабильной гемодинамики, поражения ствола левой коронарной артерии или необходимости одномоментной коррекции клапанной патологии операции производились в условиях искусственного кровообрашения (32 случая; 4,9\%).

В большинстве случаев $(354 ; 51,2 \%)$ шунтировали 4 коронарные артерии, шунтирование 3 и 5 коронарных артерий произведено в $233(33,7 \%)$ и $69(10,0 \%)$ случаях соответственно. В остальных 36 (5,2\%) случаях шунтированы 2 коронарные артерии. При этом в 656 случаях $(94,8 \%)$ передняя артерия шунтирована при помощи левой внутренней грудной артерии, индекс шунтирования составил 3,6 .

Результаты и обсуждение. Оценивались непосредственные результаты госпитального периода:

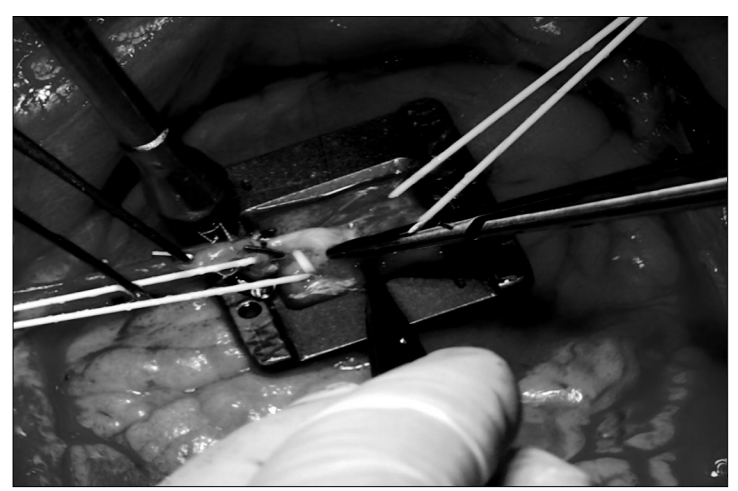

Рис. 1. Интраоперационное фото: шунтирование ПМЖА левой внутренней грудной артерией с применением стабилизатора давления

30-дневная госпитальная летальность, осложнения послеоперационного периода.

В раннем послеоперационном периоде умерло 17 больных, госпитальная летальность составила 2,5\%. Среди причин летальности преобладали периоперационный инфаркт миокарда -7 . острая сердечная недостаточность - 8. В двух случаях причиной смерти явились септические осложнения.

На графике представлена динамика летальности по годам (рис. 2).

Из данных, приведенных на графике, видно, что в первые годы хирургической активности летальность оставалась относительно высокой и снизилась до $1,25 \%$ в 2015 году, что связано с адаптацией хирургической бригады и реорганизацией кардиохирургической службы. В 2016 и 2017 годах отмечается небольшой рост летальности - до 2,5\%. В 34 случаях (4,9\%) была произведена конверсия с off-pump на on-pump АКШ, из них в 19 (2,7\%) случаях конверсия произведена по экстренным показаниям в связи с резкой дестабилизацией состояния. У остальных 15 (2,2\%) больных конверсия производилась в плановом порядке по анатомическим причинам (в связи с недоступностью сосудов).

Нами оценены факторы риска развития летального исхода в раннем послеоперационном периоде по

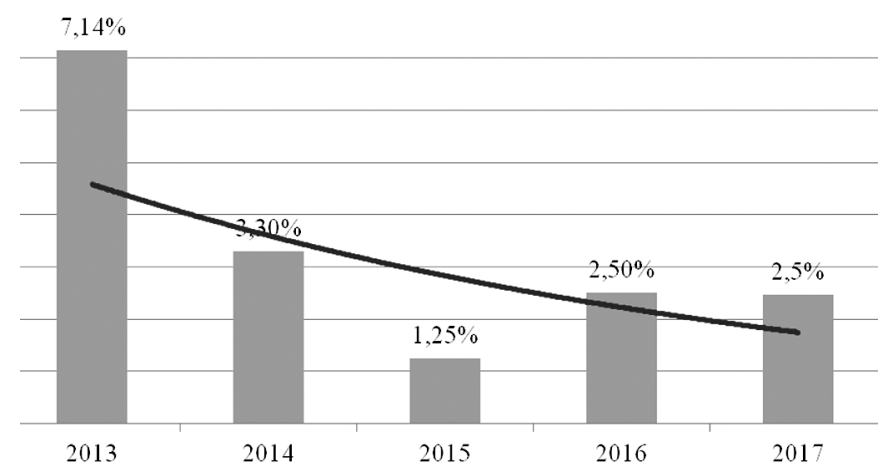

Рис. 2. График динамики летальности 
методу Хи-квадрат (с использованием автоматических систем-калькуляторов Wayne W. La Morte). B ходе однофакторного анализа мы пришли к выводу, что перенесенный в анамнезе острый инфаркт миокарда, сахарный диабет и ХОБЛ не являются факторами риска летального исхода, тогда как нестабильное состояние при поступлении (ОШ - 15,38; ДИ - 4,86-48,6; $\mathrm{p}<0,0001)$ и конверсия на on-pump по экстренным показаниям (ОШ - 30,25; ДИ - 9,46-96,7; p<0,0001) могут считаться достоверными факторами риска развития летального исхода в раннем послеоперационном периоде. Низкая фракция выброса также показала высокую вероятность развития летального исхода, однако изменения не были статистически достоверными (ОШ - 1,07; ДИ - 0,44-2,57; $=0,88$ ) (табл. 2).

Осложненный послеоперационный период отмечен у $77(11,1 \%)$ пациентов. Наиболее частыми осложнениями явились кардиальные осложнения. Так, сердечная недостаточность, потребовавшая кардиотонической поддержки, наблюдалась в 23 (3,3\%) случаях, нарушения ритма сердца - в 38 (5,5\%). Внутригрудное кровотечение отмечено в $6(0,9 \%)$ случаях, гнойносептические осложнения - в 7 наблюдениях (1,0\%). Ишемический инсульт наблюдался у 3 больных $(0,4 \%)$. Структура осложнений представлена в табл. 3.

Длительность пребывания пациентов в ОРИТ по-

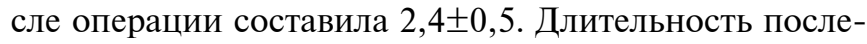
операционного периода, проведенного в клинике, составила 7,8 0,9 дней.

В средние сроки после операции (2-40 месяцев, в среднем 24,1 $\pm 0,34)$ наблюдались 377 больных $(54,5 \%)$. В период наблюдения умерло 9 (2,5\%) больных. Среди причин летальности преобладали острая сердечная недостаточность $(\mathrm{n}=3 ; 0,8 \%)$ и желудочно-кишечное кровотечение $(n=3 ; 0,8 \%)$. Данные наблюдения в отдаленном периоде представлены в табл. 4.

В средние сроки наблюдения после операции также прослежена выживаемость больных, свобода от возвратной стенокардии и свобода от повторной реваскуляризации. Так, выживаемость больных за период наблюдения до 40 месяцев составила 97,3\% (рис. 3).

\section{Таблица 2}

Независимые факторы риска летальности

\begin{tabular}{lccc} 
Показатели & OR & $\mathbf{9 5 \%}-\mathbf{C l}$ & $\mathbf{P}$ \\
\hline ОИМ в анамнезе & 0,04 & $0,01-0,18$ & $\mathrm{p} \geqslant 0,5$ \\
\hline ХОБЛ & 0,06 & $0,01-0,45$ & $\mathrm{p} \geqslant 0,5$ \\
\hline Сахарный диабет & 0,06 & $0,01-0,24$ & $\mathrm{p} \geqslant 0,5$ \\
\hline $\begin{array}{l}\text { Фракция выброса менее } \\
\text { 40\% }\end{array}$ & 1,07 & $0,44-2,57$ & $\mathrm{p} \geqslant 0,5$ \\
\hline $\begin{array}{l}\text { Нестабильное состояние на } \\
\text { момент поступления }\end{array}$ & 15,38 & $4,86-48,6$ & $\mathrm{p}<0,0001$ \\
\hline $\begin{array}{l}\text { Конверсия по экстренным } \\
\text { показаниям }\end{array}$ & 30,25 & $9,46-96,7$ & $\mathrm{p}<0,0001$
\end{tabular}

\section{Таблица 3}

Непосредственные результаты хирургического вмешательства $(n=77)$

\begin{tabular}{lcc} 
Структура осложнений & $\mathbf{n}$ & $\mathbf{\%}$ \\
\hline Сердечная недостаточность & 23 & 3,3 \\
\hline Нарушения ритма сердца & 38 & 5,5 \\
\hline Ишемический инсульт & 3 & 0,4 \\
\hline Кровотечения & 6 & 0,9 \\
\hline Гнойно-септические осложнения & 7 & 1,0 \\
\hline Итого & 77 & 11,1
\end{tabular}

\section{Таблица 4}

Причины летальности в отдаленном периоде (n=9)

\begin{tabular}{lll} 
Причины летальности & $\mathbf{n}$ & $\mathbf{\%}$ \\
\hline Острая сердечная недостаточность & 3 & 0,8 \\
\hline ТЭЛА & 1 & 0,3 \\
\hline Расслаивающая аневризма аорты & 1 & 0,3 \\
\hline ОИМ & 1 & 0,3 \\
\hline Ж/к кровотечение & 3 & 0,8 \\
\hline Итого & 9 & 2,5
\end{tabular}

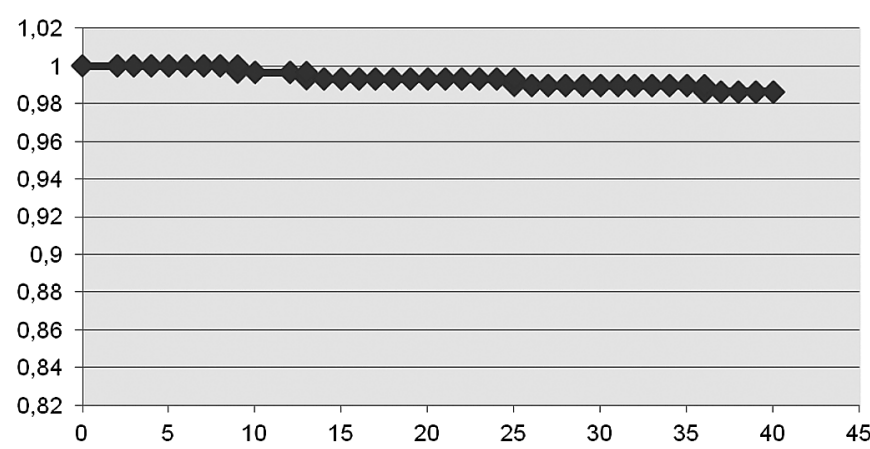

Рис. 3. Кривая Каплан-Мейера: выживаемость больных в отдаленные сроки - 97,3\%

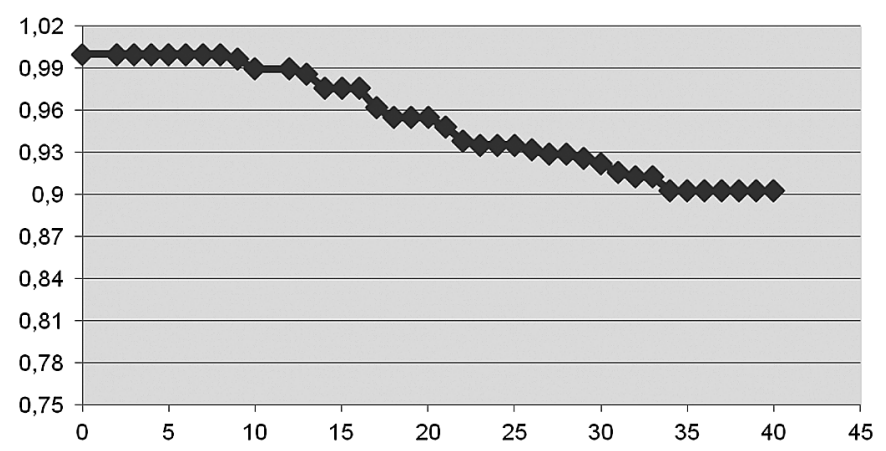

Рис. 4. Кривая Каплан-Мейера: свобода от возврата стенокардии - 90,2\% 


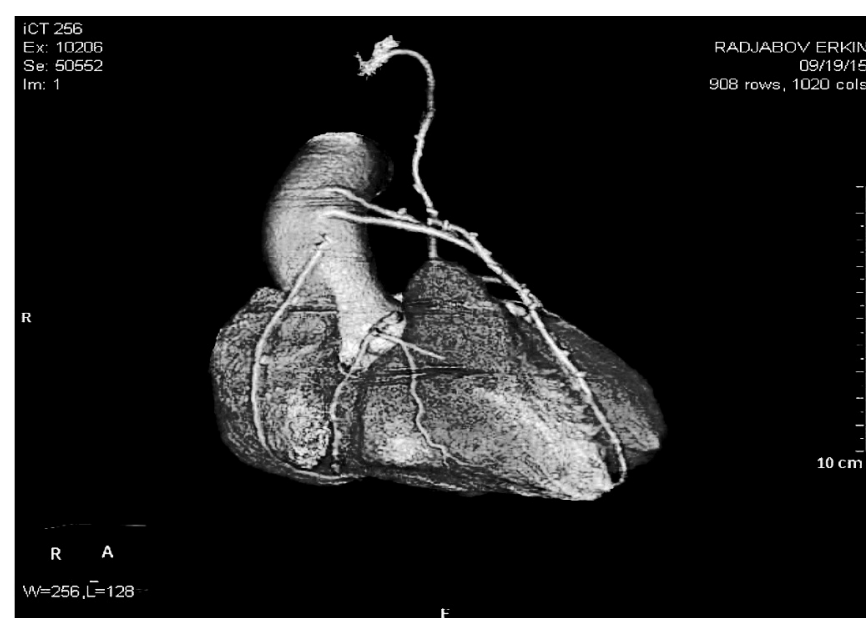

Рис. 5. МСКТ-коронарография позволяет оценить состояние наложенных шунтов: визуализируются аутовенозные графты к системе левой коронарной и правой коронарной артерий, а также ЛВГА, анастомозированная с ПНА

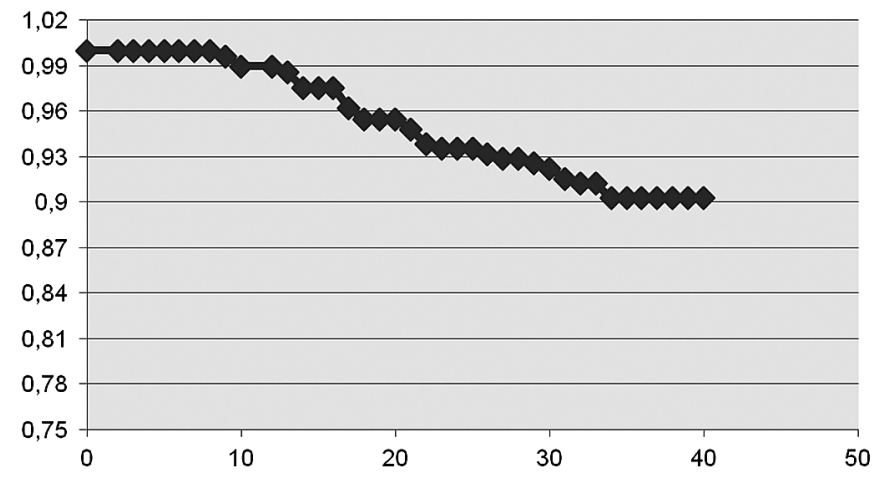

Рис. 6. Кривая Каплан-Мейера: свобода от повторной реваскуляризации - 98,2\%

Свобода от возвратной стенокардии составила 90,2\%. Это означает, что 9,8\% больных отмечали в той или иной форме возобновление стенокардических болей (рис. 4).

Данная категория больных была обследована. Скрининг-методом выявления рестеноза и функционального состояния наложенных шунтов и анастомозов выбрана мультислайсная спиральная компьютерная томография (МСКТ) (рис. 5).

При обнаружении признаков стеноза на МСKTангиографии больные подвергались ангиографическому исследованию - коронарографии и шунтографии, по результатам которых рекомендовали повторную реваскуляризацию. Повторная реваскуляризация потребовалась лишь 2 больным, у которых отмечалось прогрессирование атеросклероза в нативных сосудах. Свобода от повторной реваскуляризации составила 98,2\% (рис. 6).

Выводы. Хирургическая реваскуляризация миокарда у больных с многососудистым поражением сопряжена с низкой частотой послеоперационных осложнений, сердечной недостаточностью, нарушениями ритма сердца, неврологическими и гнойно-септическими осложнениями. Хирургическая реваскуляризация у больных с многососудистым поражением коронарного русла сопровождается относительно низкой летальностью в раннем послеоперационном периоде. Гемодинамические и анатомические причины могут способствовать переводу больного на on-pump. Независимыми факторами риска летальности являются нестабильное состояние при поступлении и интраоперационная дестабилизация гемодинамики. В отдаленном периоде МСКТангиография позволяет объективно оценить состояние коронарного русла. АКШ в среднесрочном периоде сопровождается удовлетворительной выживаемостью и свободой от реопераций и возвратной стенокардии.

\section{Литература}

1. Операции коронарного шунтирования на работающем сердце и в условиях искусственного кровообращения у больных ишемической болезнью сердца с поражением основного ствола левой коронарной артерии / Бокерия Л. А., Мерзляков В. Ю., Ключников И. В. и др. // Сердечно-сосудистые заболевания. Бюллетень НЦ ССХ им. А. Н. Бакулева РАМН. Десятая ежегодная сессия Научного центра сердечно-сосудистой хирургии им. А. Н. Бакулева с Всероссийской конференцией молодых ученых. - 2006. - Том 7, № 3. - С. 52.

2. Ишемическая болезнь сердца и факторы риска (сравнение показателей в странах Европы, США и России) / Бокерия Л. А., Ступаков И. Н., Самородская И. В. и др. // Грудная и сердечно-сосудистая хирургия. -2007 . - № 4. - С. 6-10.

3. Киладзе И. 3. Аортокоронарное шунтирование без искусственного кровообращения при коморбидных заболеваниях/ Автореферат диссертации на соискание ученой степени кандидата медицинских наук. - Москва, 2014.

4. Off-pump vs. On-pump coronary artery bypass surgery: An updated meta-analysis and meta-regression of randomized trials / Afilalo J., Rasti M., Ohayon S. M. et al. // Eur Heart J. - 2012. - Vol. 33. - P. 1257-67.

5. Results of coronary artery bypass grafting with left ventricular dysfunction (comparison of off-pump versus on-pump) / AitHoussa M., Moutakiallah Y., Abdou A. et al. // AnnCardiolAngeiol. - 2013. - 62. - P. 241-7.

6. Off-pump versus on-pump coronary revascularization: Meta-analysis of mid- and long-term outcomes / Chaudhry U. A., Harling L., Rao C. et al. // Ann Thorac Surg. - 2014. - Vol. 98. - P. 563-72.

7. On-pump versus off-pump coronary artery bypass grafting in a cohort of 63,000 patients / Chu D., Bakaeen F. G., Dao T. K. et al. // Ann Thorac Surg. - 2009. - Vol. 87. - P. 1820-6.

8. Off-pump coronary artery bypass grafting decreasesriskadjusted mortality and morbidity / Cleveland J. C. Jr., Shroyer A. L., Chen A. Y. et al. // Ann Thorac Surg. 2001. - Vol. 72. - P. 1282-8.

9. Off-pump versus on-pump coronary-artery bypass grafting in elderly patients / Diegeler A., Borgermann J., Kappert U. et al. // N Engl J Med. - 2013. - Vol. 368. - P. 1189-98. 
10. Long-term survival following coronary artery bypass grafting: Off-pump versus onpump strategies / Kim J. B., Yun S. C., Lim J. W. et al. // J AmCollCardiol. - 2014. Vol. 63. - P. 2280-8.

11. Effects of off pump and on-pump coronary-artery bypass grafting at 1 year / Lamy A., Devereaux P. J., Prabhakaran D. et al. // N Engl J Med. - 2013. - Vol. 368. - P. 1179-88.

12. Off-pump or on-pump coronary-artery bypass grafting at 30 days / Lamy A., Devereaux P. J., Prabhakaran D. et al. // N EnglJ Med. - 2012. - Vol. 366. - P. 1489-97.

13. Lazar H. L. Should off-pump coronary artery bypass grafting be abandoned? // Circulation. - 2013. Vol. 128. - P. 406-13.

14. Short-term clinical outcomes after off pump coronary artery bypass grafting at a single Veterans Affairs Medical
Center / Lushaj E., Schreiner A., Jonuzi B. et al. // Journal of Cardiothoracic Surgery. - 2016. - Vol. 11. - P. 83

15. Outcomes of off-pump versus onpump coronary artery bypass grafting: Impact of preoperative risk / Polomsky M., He X., O’Brien S. M. et al. // J Thorac Cardiovasc Surg. 2013. - Vol. 145. - P. 1193-8.

16. Concomitant off-pump coronary artery bypass grafting results in improved in-hospital outcomes for patients with ischemic mitral regurgitation undergoing surgery / Raja S. G., Husain M., Salhiyyah K. et al. // Heart Surg Forum. - 2013. - Vol. 16. - E15-20.

17. Takagi H., Umemoto T. Worse long-term survival after offpump than on-pump coronary artery bypass grafting // $\mathrm{J}$ Thorac Cardiovasc Surg. - 2014. - Vol. 148. - P. 1820-9.

\title{
Early and Midterm Results of Coronary Artery Bypass Grafting: an Emergency Center Experience
}

\author{
Khadjibaev A. M., Obeid M. A., Abdurakhmanov A. A., Mashrapov O. A., Rakhimov N. M., Abdukhalimov I. A., \\ Sabirov S. I., Ganiev U. Sh. \\ Republican Scientific Center for Emergency Medical Care (Tashkent, Uzbekistan)
}

This article is devoted to the analysis of immediate and mid-term outcomes of coronary artery bypass surgery. The study was conducted in the Republican Research Center for Emergency Medicine on 692 patients with multivessel coronary artery disease who underwent CABG surgery between 2013 and 2018 (female - 160 (23,1\%), male - 532 (76,9\%), mean age $56,04 \pm 0,9$ years). In most cases $-658(95,1 \%)$ surgical revascularization was performed on a beating heart. Off-pump to onpump conversion rate was $4,9 \%$. The mean number of anastomoses was 3,6 , early postoperative mortality rate was $2,5 \%$, the risk factors for the lethal outcome were unstable hemodynamics at admission and conversion to on-pump due to emergency reasons. Actuarial survival rate during the 40 month follow-up was $97.3 \%$. Freedom from recurrent angina and freedom from repeated revascularization was $90.8 \%$ and $98.2 \%$ respectively. Authors concluded that surgical revascularization of the myocardium in patients with multivessel coronary artery disease is accompanied by a low incidence of postoperative complications, a relatively low mortality in the early and mid-term periods of observation. CABG in our series accompanied by satisfactory indices of freedom from recurrent angina and freedom from revascularization.

Key words: coronary Artery Bypass Grafting (CABG), Ischemic heart disease treatment, on-pump CABG, conventional $C A B G$, beating heart $C A B G$, off-pump $C A B G$.

\section{Безпосередні і середньострокові результати операцій аортокоронарного шунтування в умовах Центру екстреної допомоги}

\author{
Хаджибаєв А. М., Обейд М., Абдурахманов А., Сабіров С. І., Машрапов О. А., Рахімов Н. М., \\ Абдухалімов І.А., Ганієв У.Ш.
}

Республіканський науковий центр екстреної медичної допомоги (Ташкент, Узбекистан)

Стаття присвячена аналізу безпосередніх і середньострокових результатів операцій аортокоронарного шунтування. Дослідження проводилося в Республіканському науковому центрі екстреної медичної допомоги. У дослідженні проаналізовано безпосередні та середньострокові результати АКШ, включаючи ранні післяопераційні ускладнення і смертність у 692 хворих на ішемічну хворобу серця, яким була проведена операція АКШ за період 3 2013 по 2018 роки. У більшості випадків $(658 ; 95,1 \%)$ хірургічна реваскуляризація проводилася на працюючому серці. Індекс шунтування склав 3,6 , рання післяопераційна летальність - 2,5\%. Факторами ризику розвитку летального результату стали конверсія на on-рump за екстреними показаннями і нестабільна гемодинаміка при госпіталізації. Виживаність хворих за період спостереження до 40 місяців склала 97,3\%. Свобода від поворотної стенокардії становила $90,8 \%$, а свобода від повторної реваскуляризації - 98,2\%. Висновком даного дослідження є те, що хірургічна реваскуляризація міокарда у хворих із багатосудинним ураженням супроводжується низькою частотою післяопераційних ускладнень, відносно низькою летальністю в ранньому та середньостроковому періоді спостереження. АКШ супроводжується задовільними показниками свободи від повторної стенокардії та свободи від реваскуляризації.

Ключові слова: аортокоронарне шунтування (АКШ), лікування ішемічної хвороби серия (IXC), АКШ з використанням штучного кровообігу (IK - оп-ритр), АКШ на пращюючому серці (оff-ритр). 